\title{
NOVEL FRONT METAL CONTACT PATTERNING SCHEME FOR C-SI SOLAR CELLS
}

\author{
${ }^{1}$ A.P.Sastry, Vikranth A.Chaudhary, ${ }^{2}$ Chetan S Solanki \\ Department of Energy Science and Engineering \\ Indian Institute of Technology Bombay \\ Powai, Mumbai-400076, India \\ 'sastry227@gmail.com, ${ }^{2}$ chetanss@iitb.ac.in
}

\begin{abstract}
An alternative metallization scheme for c-Si solar cells other than $\mathrm{Ag}$ screen printing, has gained importance in recent years. Metallization techniques such as two step electroplated contacts of $\mathrm{Ni} / \mathrm{Cu}$ and $\mathrm{Ni} / \mathrm{Ag}$, have shown higher efficiencies in C-Si solar cells. One of the important processes in the electroplated contacts is opening of the dielectric layer (like $\mathrm{SiN}_{\mathrm{x}}$ or $\mathrm{SiO}_{2}$ ). In this paper a novel contact patterning scheme based on use of a thermally sensitive chemical etching paste Merck, IsishapeTM is presented. Commercially processed $\mathrm{c}$-Si solar cells of area $4 \times 4 \mathrm{~cm}^{2}$ are used in the experiment. These solar cells are processed for texturization, $p-n$ junction formation, antireflective coating (ARC) deposition and back surface field (BSF), but without front metal contacts. A thermally sensitive paste from Merck, Isishape ${ }^{\mathrm{TM}}$ is used for etching the ARC. A block of stainless steel is micromachined in order to get extrusion of metal pattern similar to finger and bus bar for the front metal contact. Arrangements for electrical heating of the metal block are made. Using the electrical heaters the metal block can be heated up to $500^{\circ} \mathrm{C}$. Using the proposed technique finger lines of width $250 \mu \mathrm{m}$ are developed on the ARC coated textured $\mathrm{c}-\mathrm{Si}$ wafers. The proposed patterning technique can be used in industrial environment with high throughput.
\end{abstract}

Key words: Front contact patterning, solar cell, chemical etching.

\section{INTRODUCTION}

Alternative metallization techniques such as electroplating of $\mathrm{Ag}$ screen printed contacts [1] and electro deposited front contacts using $\mathrm{Ni} / \mathrm{Ag}$ or $\mathrm{Ni} / \mathrm{Cu}$ [2] are gaining importance. These contact techniques reduces the overall series resistance of the solar cells and hence improve their performance. One of the important processes in fabrication of these contacts is patterning of the ARC (anti reflective coating). The patterning of the ARC is most commonly done by chemical etching or using laser ablation techniques. A comparison between the chemical etching of the ARC and laser ablation techniques is reported in [3] and [4], which clearly shows the advantage of chemical etching over laser ablation. The present work demonstrates a novel patterning technique of ARC using a chemical etching paste and a metal embodiment which is in the shape of the grid pattern. The solar cells after ARC patterning are then metalized with $\mathrm{Ni}$ in a $\mathrm{Ni}$ electroless bath. The fabrication details and the results obtained are reported in the paper.

\section{EXPERIMENTAL}

The metal embodiment is made using stain less steel block (SS-316 grade) of size $4 \times 4 \mathrm{~cm} 2$ which is micromachined in the fingers - bus bar pattern. Electric heating elements of $150 \mathrm{~W}$ rating are incorporated within the metal embodiment along with temperature sensor and controller as shown in Figure 1

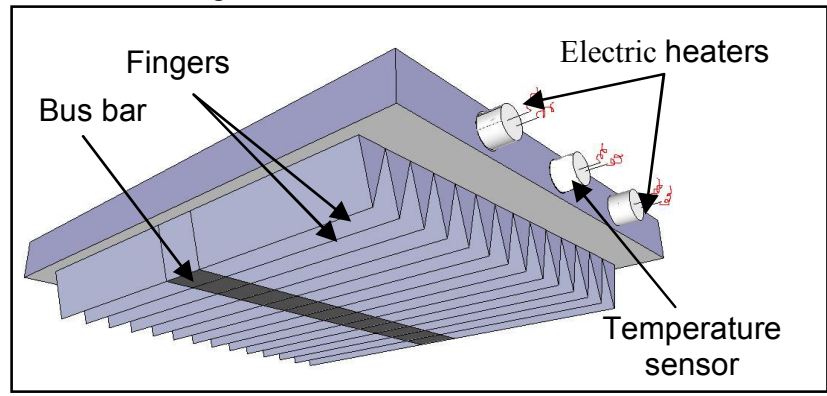

Figure 1. Schematic of metal block with finger pattern and electrical heating elements with temperature sensor

Commercially processed $\mathrm{c}-\mathrm{Si}$ solar cells without front metal contacts are used in the experiments. The cells have ARC on the top surface. The patterning of the ARC is done on these solar cells using the metal embodiment (metal block after micro-machining in the form of finger and bus bar pattern of front contact) and chemical paste for the front contact metallization. Commercially available thermally sensitive paste from Merck Isishape ${ }^{T M}$ is used for this purpose. The paste is uniformly spin coated on the solar cell and placed exactly below the finger - bus bar pattern of metal embodiment.

The metal structure is heated to $390^{\circ} \mathrm{C}$ and kept in contact with the solar cell which is coated with paste. Heat transferred from metal structure to the solar cell through the paste. Etching process can be done at the areas where the solar cell is in contact with the metal structure, which is in finger-bus bar pattern.

During heating at of the metal structure when come in contact with the solar cell, which is uniformly coated with 
paste will transfer the heat to the ARC part of solar cell through the paste as shown in Figure 2.

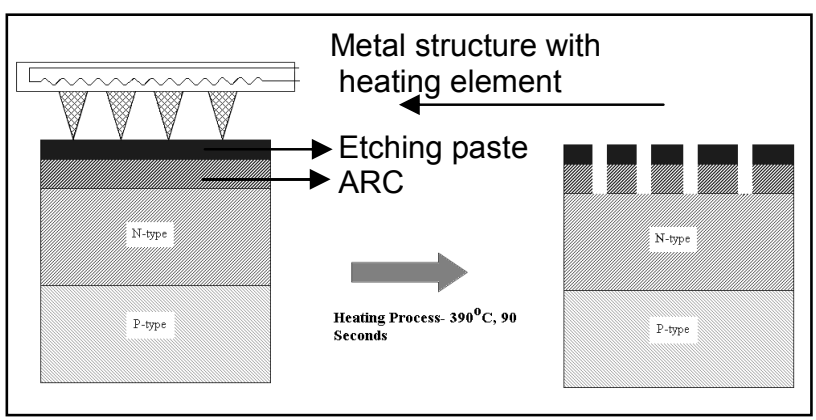

Figure 2. Etching process of Solar cell with metal structure

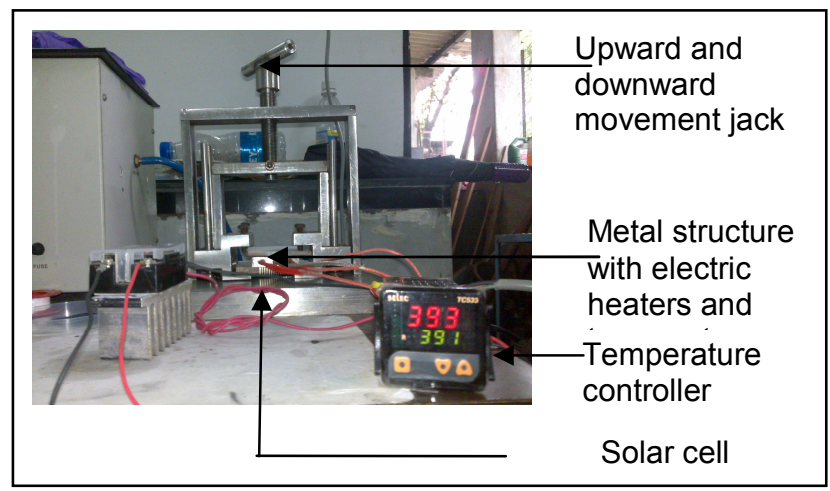

Figure 3. Metal structure with temperature controller

The metal structure is provided with a jack, to make upward and downward movements. Once, the solar cell is spin coated with the paste, it is subjected to place under the metal structure. Metal structure is heated to $390^{\circ} \mathrm{C}$ and is kept in contact with the solar cell by using jack movement as shown in

Figure 5. After $90 \mathrm{~s}$ of heating the entire structure, the metal structure is removed from the solar cell. The untreated chemical paste is removed by ultra-sonication bath. Etched pattern on the solar cell are observed under optical microscope. Uniform patterning of ARC coating over entire $4 \times 4 \mathrm{~cm}^{2}$ has been observed.

\section{RESULTS}

Chemical etching of ARC of a c-Si solar cell using a metal embodiment and temperature selective chemical paste is presented. A detailed procedure of the developed process to etch the ARC in fine finger lines is explained. Based on this process, finger widths of $250 \mu \mathrm{m}$ are obtained as shown in

Figure 5 Moreover, it is possible to reduce the finger width using this technique and experiment in this regard is in progress.

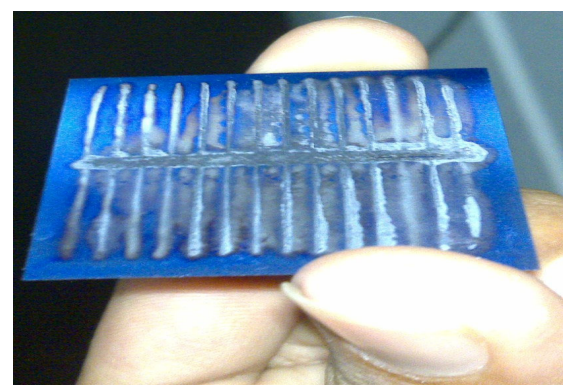

Figure 4. Shows the image of finger - bus bar pattern developed on ARC of solar cell

The patterned solar cell using metal structure is shown in Figure 4 . Some fingers are clearly visible and some are unclear because of micro machining of the metal structure. This patterning has an advantage for alternative metallization in solar cells. Further improvements in reducing the finger width and metallization procedures are

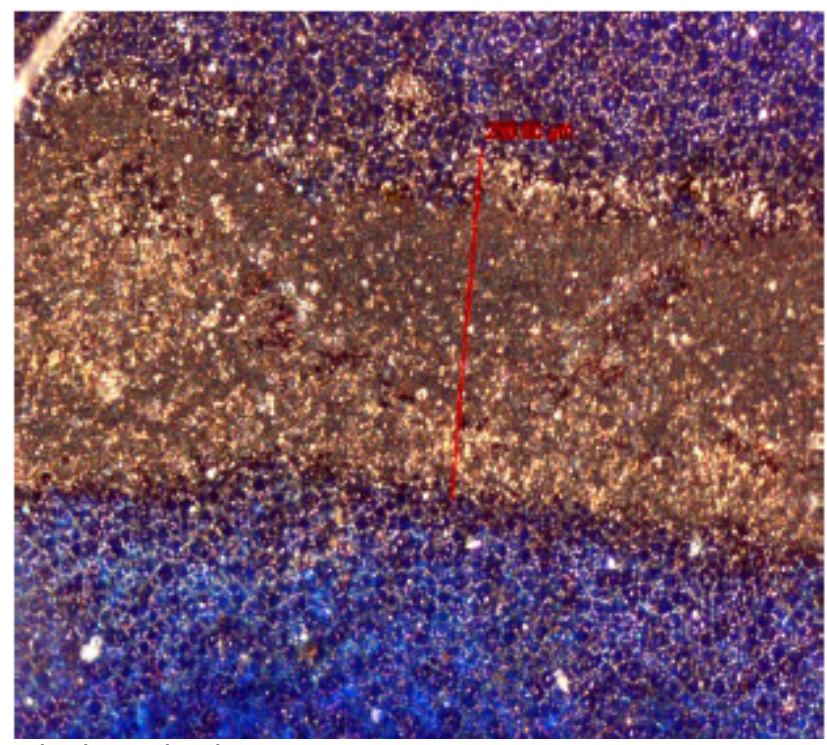

under investigation.

Figure 5. shows the image of the finger line patterned on ARC

\section{CONCLUSION AND FUTURE WORK}

It is concluded by using metal structure, the finger width of the solar cell is $250 \mu \mathrm{m}$. The finger width can be optimized by micromachining the metal structure properly.

Novel metal front contact technique is presented and etching of anti reflective coating is removed by applying Merck's Isishape ${ }^{\mathrm{TM}}$ paste to the solar cell by spin coating and heating by micro machined metal structure. It is observed that the finger width of a solar cell is $250 \mu \mathrm{m}$. 
This process has an advantage of metallization of solar cell. Solar cell taken for experiment is $4 X 4 \mathrm{~cm}^{2}$ and it can be extended up to $16 \times 16 \mathrm{~cm}^{2}$.

\section{REFERENCES}

[1] S. W. Glunz, A. Mette, M. Alemán, P. L. Richter, A. Filipovic, G. Willeke "new concepts for the front side metallization of silicon solar cells", 21st EUPVSEC, Dresden

[2] J. D. Jensen, P. Moller, T. Bruton, N. Mason, R. Russell et al., "Electrochemical deposition of buried contacts in high-efficiency crystalline silicon photovoltaic cells", J. Electrochem. Soc. 150, 2003, pp. G49

[3] Felix Book et al: "Two diffusion step selective emitter: Comparison of mask opening by laser or etching paste", Proc. 23rd ECPVSEC, Valencia.

[4] M.Bahr et al: "A new approach for the front side metallization of industrial type silicon solar cells using a structurization by etching", Proc. 22nd EPVSEC, Milan 2007.

*Indian Patent application number: 1787/MUM/2010 